\title{
UNA DEFINICIÓN (PROVISIONAL) DE CUENTO
}

\author{
A (Provisional) Definition of Story
}

\author{
Willard Marcelo Díaz Cobarrubias ${ }^{1}$
}

\begin{abstract}
RESUMEN
El presente artículo expone un conjunto de concepciones sobre el estilo literario "cuento", que fueron analizadas con el objetivo de sustraer cuatro características que definen el estilo literario estudiado.
\end{abstract}

Palabras clave: Cuento, estilo literario.

\section{ABSTRACT}

This paper presents a set of ideas about the "story" literary style, which were analyzed with the aim of removing four characteristics that define the literary style studied

Keywords: Story, literary style.

Todos sabemos qué es un cuento. Hemos oído algunos de labios de nuestra madre o los hemos leído en nuestros libros de infancia, en el colegio o en nuestros ratos de ocio. El cuento es parte casi natural de la educación en sociedad, de modo que sería innecesario definirlo. Y además, parece una empresa imposible: entre la gran cantidad de cuentos que se han escrito hasta la fecha se puede hallar multitud de tipos, temas, estilos, tonos. ¿Cómo meterlos en un solo cajón?

No obstante, los teóricos de la literatura se han esforzado por elaborar conceptos y por crear cierta regularidad justificable que permita agrupar las numerosas obras literarias que se han escrito, a fin de trabajar mejor con ellas. Así es como surgen los géneros litera- rios, las escuelas, los estilos y las definiciones. No es mucho lo avanzado hasta la fecha, pero podemos utilizar algunas ideas de la academia a fin de orientarnos en el trabajo creativo y evitar usuales embrollos.

Cuando nos preguntamos qué es un cuento estamos tratando de definir el género literario llamado cuento, esto es, hallar lo que hay común en todos los cuentos y que permite, por ejemplo, convocar a un "Concurso de Cuentos".

Las definiciones de cuento que existen son muy variadas. Juan Bosh, profesor de García Márquez, dice: "un cuento es el relato de un hecho que tiene indudable importancia". La escritora norteamericana Flannery O'Connor: "Un cuento es una acción dramática

\footnotetext{
${ }^{1}$ Maestro en Ciencias: Literatura. Docente Principal de la Escuela de Literatura de la Universidad Nacional de San Agustín. Arequipa-Perú.

Correoelectrónico:puquina@gmail.com
} 
completa, y en los buenos cuentos, los personajes se muestran por medio de la acción, y la acción es controlada por medio de los personajes". El crítico, también norteamericano, Norman Friedman: "una narración ficticia breve escrita en prosa". Cortázar usa una bella metáfora: "una síntesis viviente a la vez que una vida sintetizada, algo así como una gota de agua dentro de un cristal, una fugacidad en una permanencia". Edgardo Rivera Martínez: "una narración corta, de carácter generalmente ficticio". Kurt Spang en su libro "Géneros literarios", de 1996, dice que "Las características del cuento se pueden resumir con los términos condensación y síntesis, es decir, se construye como evento único, con pocas figuras que tienden, en una evolución dinámica, hacia el final". El argentino Enrique Anderson Imbert en su "Teoría y técnica del cuento" lo define como "una narración breve en prosa que, por mucho que se apoye en un suceder real, revela siempre la imaginación de un narrador individual. La acción - cuyos agentes son hombre, animales humanizados o cosas animadas - consta de una serie de acontecimientos entre- tejidos en una trama donde las tensiones y distensiones, graduadas para mantener en suspenso el ánimo del lector, terminan por resolverse en un desenlace estéticamente satisfactorio". Y así podríamos seguir largamente.

Un filósofo de la ciencia, Michael Polanyi, ha precisado que hay en los objetos tres niveles de características que podemos usar para hacer clasificaciones: 1) los rasgos evidentes, 2) los conocidos pero que no son fáciles de analizar, y 3 ) los rasgos indeterminados, que solo futuros descubrimientos revelarán. Sobre esa base el crítico norteamericano Charles May propone tres modos de abordar una definición de cuento. El que emplea los rasgos más evidentes, como en la definición de Edgardo Rivera Martínez o la del crítico norteamericano Norman Friedman; el que piensa que hacer una definición es difícil e innecesario porque todos intuitivamente sabemos lo que es un cuento; y el tercer modo usado por quienes sostienen que no hay ninguna definición posible de cuento porque se trata de un objeto inacabado, un género abierto y cambiante.

Parece justo y apropiado aceptar

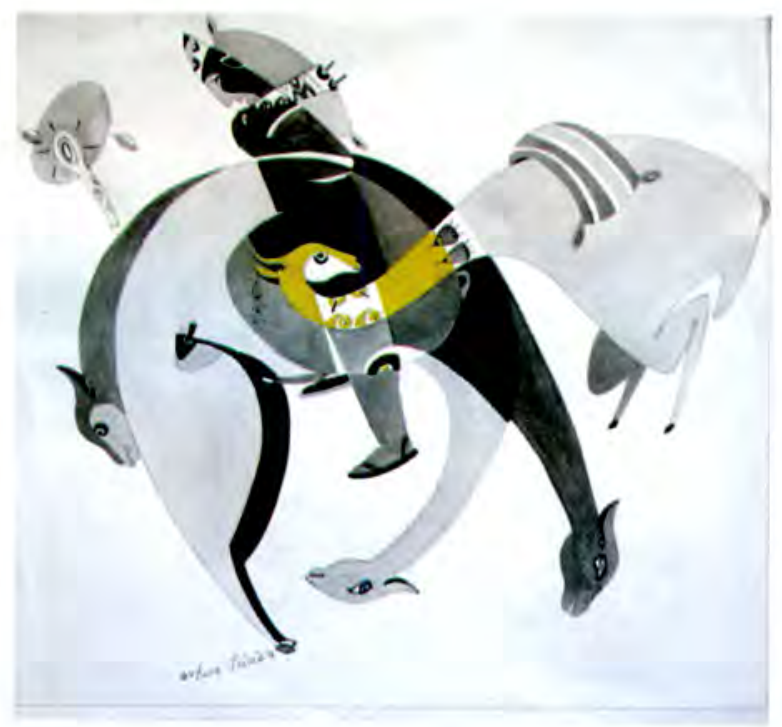


no solo una sino las tres opciones. Podemos emplear en el trabajo creativo una definición formal de cuento solo para fines didácticos, sabiendo que son necesarias más investigaciones teóricas y precisiones; y que no puede sorprendernos que un día todo el sistema clasificatorio se venga abajo ante alguna novedad radical en el arte de contar.

Con estas advertencias, trabajaremos entonces solo en el primer nivel.

Partamos de la definición escueta de Friedman según la cual un cuento es "una narración ficticia breve escrita en prosa". Es concisa y fácil de recordar, pero cada término en ella requiere una breve explicación.

\section{Narración.}

Una narración, a diferencia de una descripción, según la moderna narratología es la representación verbal de una sucesión de acontecimientos unidos entre sí por alguna intención. Para que haya narración (o relato) se necesitan al menos tres partes - un estado inicial, alguna acción que lo altere, y el resultado de esa acción-, y como lectores debemos pasar del comienzo al final de la historia siguiendo alguna lógica interna. Donde no hay esa sucesión no hay relato; una pura descripción por más poética que sea no es un relato sino una acumulación de datos característicos.

Hay que añadir que, en los hechos, no todos los cuentos presentan las tres partes clásicas, a veces basta la crisis y su desenlace, a veces el estado inicial y el momento crucial, a veces solo el momento de la transformación o crisis.

\section{Ficticia}

Un cuento es una narración corta lo mismo que una noticia de un diario o una anécdota personal. Lo que distingue a un cuento de otros relatos breves es la ficción. Por la forma son semejantes, pero por la intención práctica son radicalmente distintos.

La ficción es la naturaleza de aquellos relatos que no pretender ser verdad, que no son científicos o documentales o testimoniales o ejemplares. La ficción es

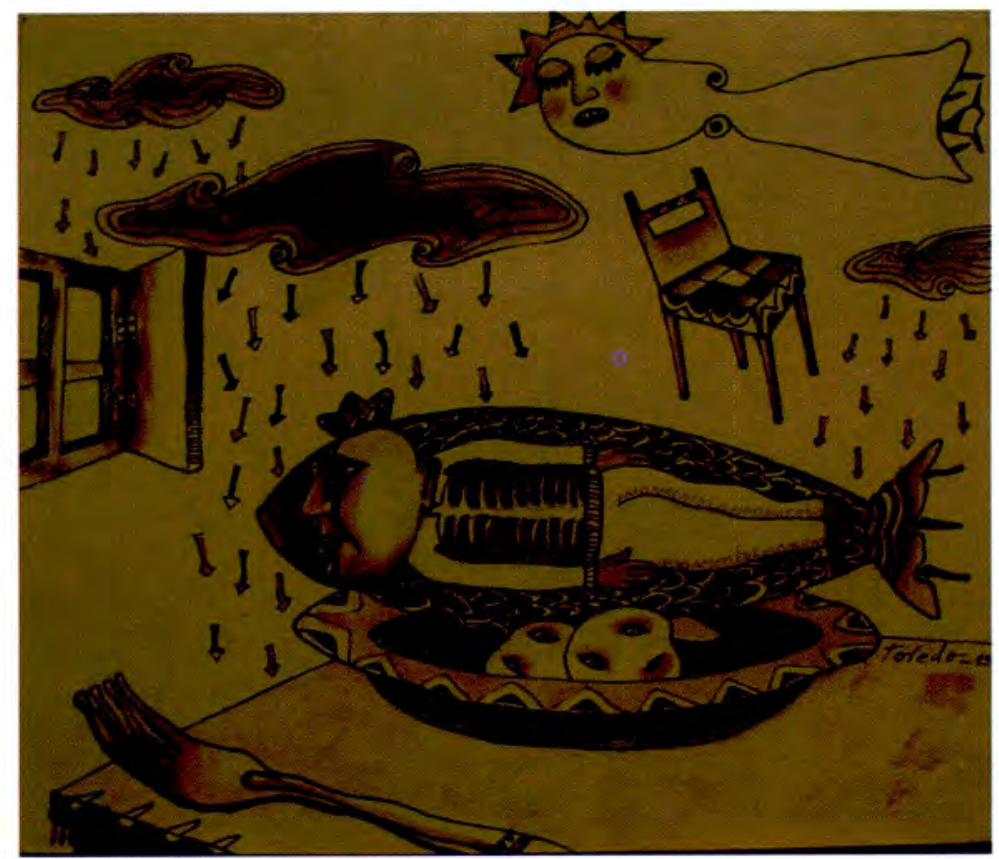


un "hacer-como-si", un fingimiento acordado entre el autor y el lector por el cual uno hace como si contara algo que ha sucedido y el otro hace como si le creyera que así fue. Es un mimetismo lúdico que no se mide con la vara de lo real.

\section{Breve}

Un cuento se lee de una sentada, decía un viejo profesor de filosofía. Para leer una novela necesitamos unos días por lo menos; para leer un cuento se requiere entre diez y treinta minutos, promedio. La brevedad hace que el cuento tenga un impacto inmediato en nosotros, alguna sensación estética existencial a la que Poe llamaba "efecto único".

\section{Escrito en prosa}

Lo cual significa que hay ciertas reglas de escritura, cierta retórica particular que el cuento desarrolla. La poesía se mide por los ritmos de sus versos; la prosa, por sus unidades fonológicas, sus armonías y sus cadencias abiertas o cerradas, consonantes o disonantes, por su musicalidad de canción en cada unidad de lectura.

Como es notorio, la definición esbozada en este artículo introductorio atiende a los rasgos formales o estructurales más que a los temas, al origen del cuento o a la sociedad en la que se crea y se publican los libros de cuentos. Al respecto hay también muchas teorías; para concluir me quedaré solo con la hipótesis de Georg Lukacs que aparece en su "Teoría de la novela".

Según Lukacs, el hombre perdió su vínculo con la naturaleza cuando se hizo racional e individualista; desde entonces busca reintegrarse, unirse a la totalidad. Un medio privilegiado en esta búsqueda es el arte; en la literatura, la épica y el drama intentan reproducir esa sensación de totalidad. "La épica grande configura la totalidad extensiva de la vida, y el drama la totalidad intensiva de la existencia", escribe Lukacs; y eso quiere decir que en drama explora las emociones, los sentimientos, las pasiones, mientras que la novela es el terreno de las ideas y la inteligencia. El cuento no podría ocuparse de totalidades, dada su brevedad; toma solo fragmentos de la experiencia para crear con ellos estructuras formales perfectas. El cuento no busca reproducir la realidad sino producir mundos cerrados que introduzcan en la imperfección de la vida una solución a la extrañeza. El que escribe cuentos tiene la mayor de las ambiciones: la perfección. Por eso, dice Lukacs, "La narración corta o cuento es la forma más puramente artística". 